\title{
Frankfurt is Calling!
}

\section{Martin Wiesmann ${ }^{1}$}

Published online: 7 February 2018

(c) Springer-Verlag GmbH Germany, part of Springer Nature 2018

Dear colleagues,

for 9 years in a row the annual meeting of the German Society of Neuroradiology (DGNR) has taken place in the Gürzenich in Cologne. These years have seen a true success story. Thanks to the efforts of many members of our society, our rather small meeting has turned into the neuroRAD, attracting more than 1000 participants. This made our meeting the largest neuroradiology conference outside the USA.

We would not be well advised, however, if we just continued as before. The needs and expectations of our participants are not the same as 9 years ago. We must preserve the qualities of our meeting, but also be daring and break new ground where it makes sense.

This is why the neuroRAD 2018 will be different!

From 2018 onwards we will be a guest at the Kap Europa in Frankfurt, which is both a comfortable and relaxing location, and one of the most modern convention centers in Europe.

NeuroRAD goes International: The neuroRAD is the meeting of the year for German neuroradiologists. That is why German will be preserved as the main congress language. Nevertheless, we will add numerous international sessions to open our meeting for English-speaking participants.

Science and Education: Many participants attend the neuroRAD predominantly for education. We acknowledge this, and will increase the number of educational lectures, work- shops, and interactive teaching, both in German and English languages. At the same time, you will see a complete makeover of our scientific sessions to make them more attractive than ever! Every session will consist of a state-ofthe-art lecture, of best-in-class research, plus short presentations by young researchers.

Keynote Lectures These will be given by Anne G. Osborn (Salt Lake City), Daniela Prayer (Vienna), Andrea Rossi (Genoa), Ingo Bechmann (Leipzig), and Önür Güntürkün (Bochum).

German Stroke School: For the first time we will host a thrombectomy course consisting of 3 days of structured interventional training with the latest simulation techniques and more hands-on time than any other course. Learn practical stroke treatment from experts in the field!

This will be Your Meeting! We will make all efforts that your scientific contributions will be visible to the community. And we will introduce various elements of online feedback so that every participant has an influence on the program, and on the scientific awards.

On behalf of the Board of the German Society of Neuroradiology, it is my pleasure to invite you to the 53rd annual conference of the DGNR, neuroRAD goes international, from 3-6 October 2018 in Frankfurt (Main).

Martin Wiesmann (Aachen)
Martin Wiesmann

mwiesmann@ukaachen.de

1 Klinik für Diagnostische und Interventionelle Neuroradiologie, RWTH, Universitätsklinikum Aachen, Aachen, Germany 